\title{
RESGATE HISTÓRICO DA PERCEPÇÃO DOS MORADORES LOCAIS EM RELAÇÃO À TRANSPOSIÇÃO DO RIO PIUMHI PARA O RIO SÃO FRANCISCO*
}

\begin{abstract}
ASSIS, André Tomé de
Mestre pelo Programa de Mestrado em Desenvolvimento Regionale Meio Ambiente do Centro Universitário de Araraquara - Uniara. Tutor da UFMG e professor do UNIFOR-MG e da SEE/MG. E-mail: andretomeformiga@yahoo.com.br RIOS, Leonardo

Doutor emEngenharia, área Ciências da Engenharia Ambiental; docente, orientador e pesquisador do Programa de Mestrado em Desenvolvimento Regional e Meio Ambiente do Centro Universitário de Araraquara - Uniara e diretor acadêmico da Escola de Engenharia de Piracicaba (EEP).

RESUMO

O rio Piumhi foi afluente do rio Grande até o final da década de 50 e, com a construção de Furnas, foi revertido para o rio São Francisco via um canal e a construção de um dique, no município de Capitólio (MG). O objetivo deste trabalho foi registrar a percepção que a população local teve da transposição do rio Piumhi por meio de jornais, livros, documentos e entrevistas, utilizando a técnica história de vida. Ficaram evidenciadas nas entrevistas percepções diferenciadas, dependendo da região geográfica onde moravam os entrevistados. Em Capitólio, ao lado do dique, o fato mais marcante foi a inundação do lago de Furnas, afetando a área rural. EntreCapitólio e o começo da zona rural de Piumhi, onde estão os canais da transposição, o fato mais marcante foi a alteração do leito do rio e das várzeas. Próximo à cidade de Piumhi, onde existia um pântano que chegava até a zona urbana, a drenagem da área alagada e transformada em área agricultável provocou conflitos fundiários. O registro da percepção da população demonstra conflitos sociais, impactos econômicos e ambientais gerados pela mudança na paisagem, registrando como as pessoas sentiram e lidaram com os fatos ao longo de suas vidas.
\end{abstract}

Palavras-chave: Transposição; Rio São Francisco; Rio Piumhi; História de vida.

\section{Abstract}

Piumhi river was a tributary of Grande river until the late 50s. The Furnas reservoir construction has reversed Piumhi river to São Francisco river through a canal and a dam in Capitólio city (MG). The aim of this study was to record the perception that local people had on the river Piumhi transposition by means of newspapers, books, documents and interviews using the life history technique. Different perceptions were evident in the interviews, depending on the geographic region where the subjects lived. In Capitólio, besides the dike, the most striking fact was the flooding of the Furnas reservoir, affecting the rural area. Between Capitólio and the beginning of rural Piumhi, where the transposition channels are, the most striking fact was the change of the riverbed and the floodplain. Near the town of Piumhi, where there was a marsh that reached to the urban zone, the drainage of the flooded area transformed into arable land caused land conflicts. The record of the population's perception demonstrates social conflicts, economic and environmental impacts generated by the change in the landscape, recording how people felt and dealt with the facts in their lives.

KEYwORDS: Transposition; São Francisco river; Piumhi river; Living history.

*Este texto deriva da dissertação (mestrado): "Transposição do rio Piumhi para o rio São Francisco: Registro Histórico" (ASSIS, 2009). 


\section{INTRODUÇÃo}

No final da década de 1950 e início da década de 1960 , o Brasil passava por um período de expectativa de forte desenvolvimento. Juscelino Kubitschek, já na sua campanha, prometeu que o Brasil teria um desenvolvimento de meio século, cresceria 50 anos em 5. Nessa perspectiva, foi construída em Minas Gerais a usina hidrelétrica de Furnas, sendo necessário construir um dique no município de Capitólio, para que as águas do lago de Furnas não inundassem a cidade e não conectasse as bacias do rio Grande e São Francisco através do rio Piumhi.

Com a construção do dique de Capitólio foi necessário transpor o rio Piumhi, que fazia parte da bacia do rio Grande, para o rio São Francisco. Para tanto, foi escavado um canal para que as águas do rio Piumhi pudessem chegar até o córrego Água Limpa, que por sua vez desemboca no ribeirão Sujo, afluente natural do rio São Francisco. Assim, o rio Piumhi passa a integrar a bacia do rio São Francisco.

O fato foi pouco divulgado e a história não teve o registro adequado e organizado, mas foi relatado em música, jornais da época, fotos e, principalmente, ficou registrado na memória da população que o vivenciou. Dessa forma, este trabalho vem provocar uma série de reflexões sobre as questões ambientais que envolvem a nascente do rio São Francisco e seu desenvolvimento local; é dentro do conceito de conservação dos mananciais que se devem discutir todas as ações direcionadas aos recursos hídricos. "Os fatos envolvendo os impactos ambientais estão sendo estudados por biólogos da Universidade Federal de São Carlos (UFSCar) e da Universidade Federal do Rio de Janeiro (UFRJ). Entretanto, os impactos históricos e sociopolíticos foram esquecidos e merecem ser resgatados e registrados." (MOREIRA, 2006, p.79).

Portanto, o objetivo deste trabalho foi realizar o resgate histórico da transposição do rio Piumhi para o rio São Francisco, não esquecendo como a população local vivenciou tal fato. Delimitou-se o contexto histórico da construção de Furnas. Fez-se uma análise observando a nascente do rio São Francisco e do rio Piumhi e o encontro desses dois rios na região dos municípios de São Roque de Minas, Vargem Bonita, Capitólio e Piumhi. Registrou se a história da transposição do rio Piumhi para o rio São Francisco, por meio do que já se tinha escrito em livros e jornais e, principalmente, através dos relatos orais colhidos pela técnica de história de vida de moradores dos municípios de Capitólio e Piumhi.

\section{Discussão TeÓRICO-METODOLóGICA}

\section{História de vida: Um elo à percepção ambiental}

A história de vida tenta obter dados relativos à experiência íntima do entrevistado que apresente resultados reveladores em relação ao tema estudado. Para Marconi e Lakatos (1999), "... é uma forma de poder explorar mais profundamente uma questão (...) há liberdade total por parte do entrevistado, que poderá expressar suas opiniões e sentimentos". Procura-se captar reações espontâneas, relatos de suas vidas. $\mathrm{O}$ investigador procura fazer uma reconstituição global da vida da pessoa e evidenciar o fato relevante ao tema, podendo colher informações que descrevam acontecimentos, emoções e sentimentos.

Segundo Bottura (1998), muitas vezes a história registrada deriva de pessoas que possuem certo poder, por muitas vezes exclui a versão de grande parte das pessoas. A técnica história de vida pode, por exemplo, colher dados de pessoas analfabetas, não rejeitando várias faces da história. As relações entre a população e o meio ambiente são fundamentais na análise de ecossistema, por isso devem ser consideradas nos planos de manejo dos recursos naturais. As informações trazidas pela população local são fundamentais.

A técnica história de vida tem demonstrado relevância para entender as relações entre homem e natureza. Para a recuperação da memória da diversidade cultural, onde houver a perda de ecossistemas naturais recorre-se ao resgate da memória, utilizando-se técnicas das ciências sociais como história de vida.

Por meio deste trabalho, pôde-se recuperar a história local sob a ótica dos seus antigos moradores, demonstrando assim a percepção deles em relação aos 
fatos. Os trabalhos de resgate da memória oral não podem ser realizados a qualquer tempo, pois dependem do ciclo de vida das pessoas. Os dados colhidos fornecem um conjunto de informações que permitem reconstruir em parte a bacia hidrográfica e seus ecossistemas, resgatam a paisagem da região no passado. Assim, pode-se situar o leitor numa retrospectiva histórica em relação à população local com o meio ambiente, bem como nas transformações no uso de recursos naturais em relação às mudanças socioeconômicas, culturais e ambientais.

A utilização da metodologia de resgate da memória ambiental pode ser ferramenta útil em regiões onde houve fortes rupturas da população com o meio ambiente. Acredita-se que este tipo de pesquisa pode fornecer subsídios para programas de educação ambientais mais compreensivos, baseados nas representações e percepções das populações, evitando-se, dessa forma, o desencontro entre os educadores e as comunidades, desencontro este que resulta da diferença entre os códigos científicos e as representações culturais formadas na relação entre as comunidades e seu meio ambiente.

Na pesquisa, quando se quer ir direto ao assunto a ser investigado, é utilizada a técnica do depoimento, em que são colhidas determinadas informações pessoais, cabendo ao pesquisador conduzir com sensibilidade o depoimento do sujeito, para mantê-lo dentro do tema proposto. O depoimento é curto e com maior interferência do pesquisador.

Segundo Whitaker (2002), numa tentativa de transcrever na íntegra as falas do homem rural, as transcrições das entrevistas devem ter o cuidado de não fazer uma caricatura desse homem, pois transcrever a fala na íntegra para a palavra escrita possui suas limitações:

"(...) O alfabeto que utilizamos em qualquer atividade, acadêmica ou não, não é um alfabeto fonético. Não dá conta, portanto, da imensa variedade de pronúncias das sociedades complexas. (...) Estamos preocupados com o homem rural porque ele tem sido vítima indefesa de transcritores bem intencionados que julgam estar respeitando seu discurso e conseguem reproduzir apenas a caricatura de sua pronúncia." (WHITAKER, 2002, p.115, p.116, p. 117).

\section{A transposição do rio Piumhi}

A transposição do rio Piumhi aconteceu entre o final da década de 1950 e início da década de 1960, quando estava sendo construída a usina hidrelétrica de Furnas, que se situa no centro-oeste de Minas Gerais. Um dos problemas encontrados foi que, com o alagamento da represa, as bacias do rio Grande e do rio São Francisco seriam conectadas pelo rio Piumhi. Sendo assim, o rio Piumhi, que era afluente do rio Grande foi desviado de seu curso e passou a ser afluente do rio São Francisco. Foi construído um dique na cidade de Capitólio (vizinha à cidade de Piumhi e Vargem Bonita), que separaria as águas represadas de Furnas do encontro com as águas do rio Piumhi.

$\mathrm{O}$ rio Piumhi, próximo à cidade de Capitólio, formava umpântano e, segundo Moreira(2006), existia um pantanal por onde corria o leito do rio Piumhi. Foi feito um sistema de drenagem e o rio passou a correr por um canal artificialmente construído. Desviando as águas do pantanal e de seus afluentes para o córrego Água Limpa, que deságua na margem esquerda do Ribeirão Sujo, um dos afluentes da margem direita do rio São Francisco:

"A cabeceira do rio Piumhi está localizada na divisa entre municípios de Vargem Bonita e Piumhi, ao centro-oeste do Estado de Minas Gerais. Sua cabeceira é formada pela junção dos córregos Destêrro, Jorça e Confusão aproximadamente a 930 metros de altitude.

No final dos anos 50, as águas do rio Piumhi fluíam num pequeno trecho para o nordeste, deslocandose para o leste, em seguida para o sudeste e finalmente para o sul, que passava a ser sua direção geral até a foz. Em parte de seu percurso atravessava uma região de planície alagada com mais de $38 \mathrm{~km}$ de extensão, denominada antigamente como o pantanal do rio Piumhi. À 
margem esquerda desse rio está localizada a cidade de Capitólio, onde as águas do Piumhi continuavam rumando ao sul, por volta de $760 \mathrm{~m}$ de altitude, onde se situava sua foz, na margem direita do rio Grande. Portanto, até 1963 o rio Piumhi pertencia a bacia do rio Grande. Segundo as folhas cartográficas de Vargem Bonita, rio Piumhi, Piumhi e Capitólio (escala 1.50.000), os principais afluentes do rio Piumhi, à margem direita, são córregos da Jorça, da Confusão e da Estiva, ribeirão dos Pavões, córregos dos Bois, da Onça, do Servo, Campão Grande, do Fumo, Mutuca, Penedo, ribeirão da Cachoeira e córregos Àgua Limpa, dos Soares e Araujo. Os afluentes da margem esquerda são córregos do Destêrro, das Almas, ribeirão dos Almeidas, córrego Capão da Olaria, ribeirão das Minhocas e os córregos Pari Velho e Engenho da Serra. Ressalta-se que até o inicio dos anos 60 os córregos Capão da Olaria, dos Bois, da Onça, do Servo, Campão Grande, do Fumo e Mutuca não desaguavam diretamente nas margens do rio Piumhi, mas sim no grande pantanal por onde percorria o rio Piumhi. (...) Aproveitando a topografia da região do pantanal - por onde corria o leito do rio Piumhi, suas lagoas marginais e seus 22 afluentes - foi efetuado um sistema de drenagem, com a construção de aproximadamente $18 \mathrm{Km}$ de canais, alterando o curso do rio Piumhi, desviando as suas águas e as do pântano para o córrego Água Limpa, que deságua na margem esquerda do ribeirão Sujo, um dos afluentes da margem direita do rio São Francisco. Para efetuar o desvio, foi necessário alterar o leito do córrego Água Limpa, que foi totalmente dragado e alargado para receber todo o volume de águas vindas do rio Piumhi, de seus afluentes e da drenagem do pântano. $\mathrm{O}$ mesmo procedimento teve de ser feito em parte do leito do ribeirão Sujo. Na parte inferior da bacia do rio Piumhi, na região do dique, formaram-se sucessões de grandes lagos interligados, cujas àguas também foram desviadas para um dos canais do rio Piumhi (canal de refluxo), que se junta ao canal construido sobre o Àgua Limpa" (MOREIRA, 2006. Disponível em http://www.transpiumhi.ufscar.br/historico.htm. Acesso em: 12 janeiro de 2009).

\section{A construção do dique de Capitólio}

Segundo Rainer (2002), com a construção de Furnas cidades seriam inundadas, caso de Guapé, reconstruída ao lado da cidade velha. $\mathrm{O}$ mesmo teria acontecido com a cidade de Capitólio, se a barragem tivesse seguido o projeto inicial. O projeto Dique 1 deveria ser construído num espigão no município de Piumhi. Esse dique seria relativamente baixo e sua construção, bem vantajosa para Furnas, pois o investimento seria o mínimo e o reservatório bem maior. A cidade de Capitólio ficaria, portanto, praticamente submersa uma vez que a água atingiria o piso da igreja matriz. Diante da iminente inundação o protesto popular foi tão grande, contando com o apoio do vigário Alberico Santos, que Furnas recuou e elaborou um segundo projeto (Projeto Dique 2).

No segundo projeto, o dique seria colocado entre a fazenda Matinha de Sinval Alves de Melo e a fazenda de Francisco Delfino, no local onde se vêo trecho mais estreito do lago de Furnas, quando se vai do atual dique em direção à ilha do Funil. Sondagens geotécnicas chegaram a ser realizadas para dar início à construção, mas faltava, naquela região pedregosa, terra para a construção do dique. $\mathrm{O}$ transporte teria de ser feito a uma distância de 2 quilômetros. Realizou-se então um terceiro estudo, o projeto dique 3 , que finalmente culminou na construção do dique atual, na fazenda do sr. Antônio Jonas. Duas vezes mais extenso que o projeto anterior, havia no local terra adequada e disponível. Em dezembro de 1960 o bispo diocesano celebrou uma missa campal no lugar onde seria o dique - que tem 650 metros de extensão e foi construído pela construtora Mendes Junior, sendo o engenheiro dr. João Câncio Fernandes Filho seu supervisor-técnico.

\section{Metodologia}

\section{Levantamento bibliográfico}

A obtenção de dados se deu a partir de pesquisas 
de exploração, nos levantamentos de fatos históricos na bibliografia de jornais locais da região de São Roque de Minas, Vargem Bonita, Capitólio e Piumhi; no acervo bibliográfico das bibliotecas municipais; no acervo de dados do escritório do Ibama e do parque nacional da Serra da Canastra, no município de São Roque de Minas; e em trabalhos relacionados ao tema, como monografias, dissertações, teses e pesquisas técnicas de diferentes órgãos do governo e instituições de ensino.

\section{História de Vida e Depoimentos Aplicação da técnica}

Considerando amostragem de depoimentos em diversos pontos dos municípios, em diferentes níveis socioeconômicos, temos uma visão geral de como os moradores perceberam a história. Foram entrevistados com a técnica história de vida sete moradores locais. A análise começa no dique de Capitólio e vai até a foz do rio Piumhi no rio São Francisco, no município de Piumhi.

Foram colhidos dados qualitativos, de caráter descritivo, emocional e afetivo, por meio de entrevista não estruturada, não dirigida, através da técnica de história de vida. A escolha e o número de entrevistados não seguiram um padrão rígido; procurou-se identificar, ao longo do curso dos rios, moradores que viveram na época da transposição do rio Piumhi ou que tenham demonstrado conhecimento da história ou se sentiram afetados por ela. Moradores que tenham uma ligação de modo de vida com os rios, seja ela econômica, social ou ambiental. As entrevistas visaram coletar percepções frente às questões históricas, as transformações geradas pela transposição e a importância do rio São Francisco e do rio Piumhi, com elementos representativos como as responsabilidades, interesses, possibilidades de uso, expectativas, valoração.

As primeiras perguntas procuraram identificar a base da amostra, como a idade, o nível de conhecimento da história da transposição e a ligação social, econômica e ambiental com os rios. Ao longo da entrevista, foram observadas as respostas que se colocaram a favor e contra a transposição e a valorização de impactos ambientais, sociais e econômicos, em diferentes grupos socioeconômicos, com idades que demonstrem conhecimentos da história - não se tentou fazer com que as respostas seguissem caminhos rígidos, dando ao entrevistado liberdade para demonstrar fatos que ainda não eram conhecidos.

Inicialmente, a técnica de história de vida era a metodologia escolhida, mas percebeu-se durante as entrevistas as dificuldades de se trabalhar adequadamente a técnica; as entrevistas de história de vida, no caso da transposição do rio Piumhi, levariam um tempo muito grande para serem realizadas, podendo levar dias, e por vezes não se concretizou por inteiro, sendo que o entrevistador teve de direcionar mais rapidamente o foco da pesquisa, adequando a pesquisa para a técnica de colher depoimentos. Em todos os casos durante a "conversa" os entrevistados contaram histórias de suas vidas, lembrando desde a infância até o presente, os parentes que viveram com eles ao longo desse tempo; houve momentos de profunda emoção. A paisagem da região foi lembrada e apresentada pelos entrevistados.

\section{Sujeitos da pesquisa}

População que mora ao longo do curso do rio Piumhi nos municípios de Capitólio e Piumhi, ou que acompanhou a história da transposição e a importância do rio São Francisco e rio Piumhi na região.

\section{Análise dos resultados}

Foi feita a transcrição dos relatos tentando ser fiel ao máximo à íntegra das entrevistas. De acordo com a revisão da literatura já apresentada, muitos sons e emoções, por vezes, não são fáceis de se transcrever. Em seguida, os relatos se foram incorporando às referências bibliográficas, às falas de outros entrevistados da mesma região geográfica, para depois serem recortados, focalizando os principais pontos desejados na pesquisa. Ainterpretação deu-se a partir de comparações com os diferentes relatos e o referencial bibliográfico. Os resultados se apresentam como exemplos dos fatos registrados em diversos 
documentos, bem como expõem o sentimento e a visão da população local. Para tanto, as entrevistas foram gravadas com gravador digital, mediante consentimento dos entrevistados.

\section{Resultados E Discussão}

A história retratada nas margens do rio Piumhi

A região da transposição do rio Piumhi abrange áreas diversas. Por meio dos depoimentos colhidos entre os moradores das margens do rio Piumhi podese descrever parte da história da transposição, observando como as pessoas acompanharam as mudanças na paisagem. Portanto, dependendo da localização geográfica do morador, as mudanças foram sentidas e relatadas de maneiras diversas. Foram evidenciados três grupos distintos de percepção: na área do município de Capitólio, próximo ao lago de Furnas; na área rural entre Piumhi e Capitólio; e na região próxima ao antigo pântano do rio Piumhi, junto à área urbana do município de Piumhi, que secou e onde hoje são praticadas a agricultura e a pecuária comercial. Nos subitens abaixo estão descritos esses fatos.

\section{Capitólio: O retorno do rio Piumhi pela construção do dique}

A construção da hidrelétrica de Furnas transformou radicalmente a vida dos capitolinos. Houve muitos danos, visto que as melhores terras foram encobertas. Segundo Rainer (2002), cerca de 22,4\% da área total do município, que é de 522,3 km quadrados, foi inundada. A água subia rapidamente, plantações de arroz e milho ainda verdes, tulhas cheias de cereais, casas, benfeitorias, engenhos de cana, moinhos... Mal dava tempo de derrubar as paredes das casas para aproveitar algo, até animais não foram todos retirados a tempo. Aindenização foi a preço de escritura. Como as escrituras eram registradas a preços inferiores, em razão de impostos, a indenização foi baixa. Muitos fazendeiros foram morar na Vila Vicentina, uma instituição de caridade de Capitólio. Houve suicídios e vários causos de neuroses profundas. A população do município caiu. Segundo o Censo do IBGE de 1950,
Capitólio tinha 6.643 habitantes, 5.668 na zona rural e 975 na área urbana. Quatro décadas depois, no Censo Demográfico de 1991, o município apresentava 4.177 habitantes, 1.432 na zona rural e 2.745 na urbana. Atualmente, segundo o site oficial da Prefeitura de Capitólio, a cidade possui cerca de 8 mil habitantes. Apesar de tantos problemas, a represa de Furnas trouxe muito progresso. A região ficou bem servida de energia e foi construída a rodovia que liga Passos a Formiga, passando por Piumhi, e a região foi transformada num enorme potencial turístico com o lago de Furnas. Muitos jovens hoje aproveitam das vantagens que o lago de Furnas trouxe, mas não sabem do trauma que seus avós sofreram.

Na época o governo era tipo uma ditadura. A gente acompanhou a construção, eu era muito pequeno, mas eu lembro, lembro as máquinas trabalhando, nossa casa dava vista. A gente via a barragem.

Indenizou. Claro que não era pelo valor real, sempre muito menos.

Teve muita resistência, o povo recebeu muito menos que valia. O pessoal ficou triste. Na maioria. (Depoimento do sR. José Carlos Soares Carlito)

Como se pode perceber no depoimento acima, fica clara a insatisfação da comunidade local, principalmente com relação ao pagamento irregular das indenizações pagas pelo governo pelas terras ocupadas pelo lago de Furnas. Também foi colocada a questão do governo tipo "ditadura", em que a população não tinha voz, e novamente o sentimento de perda do lugar de vivência - levando até a suicídios. Como já foi relatado, o lugar é um espaço que envolve relações afetivas e às vezes não pode ser totalmente reconstruído, provocando traumas psicológicos que podem levar à morte. Os benefícios da construção do lago também são colocados, como a construção do bairro de luxo em Capitólio e os turistas que o frequentam e movem atualmente a economia do município.

Segundo o jornal Alto São Francisco de 24 de novembro de 1956, no auge dos protestos realizados 
pela população local, Juscelino Kubitschek respondia que as manifestações só estavam ocorrendo por ignorância, por não conhecimento da importância da obra para manter a qualidade de vida da população local. Ele alardeava um déficit de energia elétrica que estava retardando o desenvolvimento, e a construção da usina de Furnas inundaria de energia o sul de Minas Gerais. Que nenhum quilowatt, dos 500 mil destinados a Minas Gerais seriam desviados a outras regiões e lembrava que os donos dos terrenos alagados receberiam as devidas indenizações.

Difícil avaliar, né? Tinha a necessidade de uso de energia; o que move o país é a energia, né? Mais os problemas sociais na época foram muitos, né? Pra quem teve terra inundada pegar o dinheiro, investir em outra coisa, embora o valor; quem fez isso foi melhor do que quem foi brigar. Foi difícil pra muita gente. Que não queriam sair das casas, tiveram de ser arrastados. Falaram que não ia sair que ia ficar na casa, ia ficar lá, os vizinhos tiveram de ir lá e retirar. Teve alguns casos assim. (DEPOIMENTO DO SR. JOSÉ CARLOS SoARes CARLito)

As falas registradas no jornal demonstram a ideologia desenvolvimentista e, em contrapartida, as colocações do depoimento sobre retirar pessoas à força de suas casas em nome dessa política. Foram citados benefícios sentidos na vida dos entrevistados, como o caso das pessoas que possuem o hotel, construído para receber os turistas na atualidade, um contraponto entre os malefícios iniciais da construção do lago, e benefícios das adaptações da família ao novo lugar.

No entanto, essa comparação é meramente especulativa, pois não existe parâmetros para comparar duas situações em tempos tão diferentes. Como seria essa região caso a represa não existisse? Essa é uma resposta impossível de ser dada. O certo é que a inundação para a construção do reservatório de Furnas causou diversos problemas ambientais e sociais na região, e estão vivos até hoje na memória da população que vivenciou o fato.

\section{Piumhi: Os canais da transposição}

Com a construção do dique de Capitólio, o rio Piumhi teve de ser desviado para o córrego Água Limpa através de um canal artificial. Como as águas do rio Piumhi corriam no sentido de Capitólio, foi necessário aprofundar o leito do rio Piumhi, fazendo um outro canal, para que as águas que drenam o município de Capitólio pudessem ser escoadas também para o rio São Francisco, através do córrego Água Limpa e do ribeirão Sujo. Sendo assim, o rio Piumhi hoje corre para o rio São Francisco em canais artificiais, canais naturais de um córrego e depois um ribeirão, o que provocou um aumento significativo de volume nesses corpos d'água, causando problemas de erosão. Portanto, o rio Piumhi, o córrego Água Limpa e ribeirão Sujo tiveram suas estruturas alteradas, ficando sem mata ciliar, desprovidos de proteção. Uma forte alteração no ecossistema regional.

Enche, agora que enche direito. As vargens tá tudo cheio. Fez o dique lá, pois então tampou, a água corre mais não corre tudo, água num tem espidiência, então a água num corre, tá tudo cheio. (Depoimento da SRA. Maria Alves FerReira)

Não foi fácil achar moradores na região que acompanharam as obras da transposição, que estavam antes na região e que lá ainda estão. A maioria dos moradores tinha se mudado para a região recentemente. Portanto, essa é uma das últimas oportunidades de se descrever a história a partir das falas dos moradores. Nos depoimentos acima, percebe-se o início das obras sendo relatado. A obra não foi bem-feita. Foi feita às pressas e os canais não foram feitos com a profundidade correta, de acordo com os moradores, por isso as inundações ocorrem em Capitólio.

\section{Piumhi: Alterações no pântano, foz do rio Piumhi}

Segundo Moreira Filho (2006), para mudar o curso do rio Piumhi foram construídos canais. $\mathrm{O}$ rio Piumhi formava um pântano que foi dragado, e os córregos 
da região passaram a se juntar a essas águas e escorrer por esse canal. "Portanto, o rio Piumhi e seus 22 afluentes passaram a correr por aproximadamente 18 quilômetros de canal até o córrego Água Limpa. Em parte de seu percurso atravessava uma região de planície alagada com mais de $38 \mathrm{~km}$ de extensão, denominada antigamente como o pantanal do rio Piumhi" ( MOREIRA, 2006). Atualmente, o rio Piumhi vem tanto de suas nascentes, na divisa do município de Piumhi e Vargem Bonita, como do refluxo do município de Capitólio, através de um canal artificialmente construído e se encontra, no município de Piumhi, com o rio São Francisco.

Atravessava aquilo era de canoa. Extensão grande assim. Meu sogro era de lá do pântano, era como se fosse uma lagoa. Ele pegava de Vargem Bonita, até Capitólio. Pegava um terreno bom de Piumhi, pegava tudo. Depois veio um português morando aqui em Piumhi, ele fez um aterro. No caso, de carro de boi, no braço, montou pedra pelo pântano afora e abriram uma estrada.

Depois veio essa drenagem do rio. E o aterro desapareceu. O aterro tinha uns 500 metros de comprimento, passou até a ponte. (DEPOIMENTO DO SR. JAMIL)

Por esse depoimento se percebe que essa região do rio Piumhi formava uma grande extensão alagada, que os moradores tinham desejo de aproveitar para agricultura e pecuária. Antes da transposição do rio Piumhi, houve tentativas de aterro. Nas entrevistas nessa área, foi difícil tentar levar o entrevistado a relatar impactos ambientais, pois o desejo de todos os entrevistados era falar sobre a questão fundiária. Quando o pântano secou, essa área foi ocupada por grandes fazendeiros. Atualmente, grandes latifundiários. As entrevistas nessa área não ocorreram na zona rural; antes a região era um pântano, portanto, sem moradores. A região é muito grande e não se encontraram moradores perto, pois hoje, como foi dito, são grandes fazendas. As entrevistas foram realizadas com moradores que habitavam, na época, as proximidades dessa região rural, e hoje vivem na cidade de Piumhi. Houve algumas tentativas de falar com os grandes fazendeiros, mas não foram conseguidas as entrevistas.

\section{Conclusões}

A transposição do rio Piumhi tem percepções diferenciadas, dependendo da região geográfica do morador ao longo do rio, onde foram colhidas as informações.

No município de Capitólio, próximo ao lago de Furnas, a construção da barragem e a inundação das áreas mais férteis do município, fundo de vales, marcaram profundamente os moradores, como evidenciado nos relatos de casos de neuroses e até suicídios provocados pela falta de referência da história familiar e a perda do sentimento de pertencimento de parte da população.

$\mathrm{Na}$ área rural de Capitólio e Piumhi, onde foi construído o canal de transposição, o fato mais marcante para os ribeirinhos foi a transformação do leito do rio, provocada pela abertura dos canais de transposição e a falta de peixes, emrazão da drenagem do pântano de Piumhi.

$\mathrm{Na}$ área onde o rio Piumhi formava um pântano antes da transposição, ficou marcada a questão fundiária. Aárea drenada se transformou em terras agricultáveis de excelente qualidade, devido ao sedimento depositado no antigo pântano. Essa área se tornou em um ponto de conflito pela disputa de terras, pois quando pântano não havia proprietários. Movimentos de trabalhadores sem-terra e proprietários rurais disputaram a área e até hoje a desavença gera discussão e sentimentos de injustiça por parte da população.

Os impactos sociais e econômicos foram notados pela comunidade local, porém, os impactos ambientais, às vezes por falta de conhecimento técnico ou pela pouca importância que tinham na época da transposição, foram escassamente evidenciados nos relatos da comunidade local e dos meios político, acadêmico e empresarial, e estão sendo agravados ao longo da história. A transposição do rio Piumhi é uma obra pouco lembrada e seus impactos no rio São 
Francisco, pouco estudados, por não comprometerem de forma tão visível a economia e o meio ambiente do rio São Francisco para população em geral.

Devido à importância do tema, torna-se necessário o debate da questão da transposição de rios, principalmente quando se inicia a transposição do rio São Francisco no Nordeste brasileiro. A ênfase dada à construção das obras e os valores aplicados nessa fase são vultuosos. Porém, com o passar dos anos, a população local fica com o ônus dos impactos ambientais e sociais e a manutenção das áreas modificadas são negligenciadas pelo poder público e privado.

\section{REFERÊNCIAS}

BOTTURA, Giovana. A compreensão das formas de relação da população com o meio ambiente: estudo de caso no reservatório de Salto Grande (Americana-SP). 1998. 122 f. Dissertação (Mestrado em engenharia ambiental), USP, São Carlos, SP., 1998.

HOCHBERG, E. Julian. Percepção. New Jersey, Estados Unidos da América: Prencite-
Hall Inc, 1966. 179 p.

MARCONI, Marina de Andrade; Lakatos, Eva Maria. Técnica de pesquisa: planejamento e execução de pesquisas, amostragem e técnicas, elaboração, análise e interpretação de dados. São Paulo: Atlas, 1999. 260 p.

MOREIRA FILHO, Orlando. Uma transposição de rio esquecida. Revista UFG. Goiânia, n. 2, ano 7 p.78-82, Dez. 2006. Disponível em http:// www.transpiumhi.ufscar.br/divulgacao.htm. Acesso em: 21 abril 2007.

RAINIER, Adil. Capitólio em Prosa e Verso. Viçosa: Editora Folha de Viçosa, 2002. 295p.

THOMPSON, Paul. A voz do passado. História Oral. São Paulo, Paz e Terra, 1992.385 p. WHITAKER, Dulce C. A. Sociologia Rural Questões Metodológicas Urgentes. São Paulo: Editora Letras à Margem, 2002. 256 p.

http://www.capitolio.mg.gov.br/default.asp. Acesso em: 8 maio 2007. 